\title{
Olmiana argentina, a new genus and species of Achilidae (Hemiptera, Fulgoromorpha) from Argentina.
}

\author{
A. GUGLIELMINO ${ }^{1,4}$, C. BÜCKLE ${ }^{2} \&$ A.F. EMELJANOV ${ }^{3}$ \\ ${ }^{1}$ Department of Plant Protection, University of Tuscia, Via S. Camillo de Lellis, 01100 Viterbo, Italy. E-mail: guglielm@unitus.it \\ ${ }^{2}$ Neckarhalde 48, 72070 Tübingen, Germany \\ ${ }^{3}$ Zoological Institute, Russian Academy of Sciences, St. Petersburg, 199034 Russia \\ ${ }^{4}$ Corresponding author
}

\begin{abstract}
The first record of the planthopper tribe Achilini from Argentina is established with the description of Olmiana argentina gen. and sp. nov.. Details of the fifth larval instar are described. The systematic position of the new genus within the Achilidae is discussed, and a key to the genera of the subtribe Achilina is provided.
\end{abstract}

Key words: Achilinae, Achilini, Achilina, fungus bugs, planthoppers

\section{Introduction}

Achilidae are widely distributed both in temperate and tropical regions. As far as is known, the juvenile instars live under the bark of decaying logs and feed on decaying vegetation or fungi; the adults occur above ground on their hosts, in rotten wood or stumps and feed on the sap of higher plants (O'Brien 1971; Wilson et al. 1994).

To date, all Achilidae recorded from South America belong to the subfamily Achilinae within three supertribes: Myconites, Apatesonites and Achilites (Emeljanov 1991, 1992; Fennah 1945a, 1945b, 1950, 1965).

The supertribe Myconites is represented by one species of Rhotala (Rhotalini) from Chile, one species of Myconellus (Myconini) in Argentina, two species of Myconus (Myconini) from Brazil and 13 Plectoderini species, belonging to seven genera, distributed in Chile, Brazil, Ecuador and British Guyana, one of them occurring also in Panama.

The Apatesonites include three species of Sevia (Seviini) from Brazil. The supertribe Achilites is represented by taxa only within the tribe Achilini.

All currently known South American Achilini (ten species from eight genera) belong to the subtribe Elidipterina (Emeljanov 1992) and are distributed in the tropics, north of Argentina. Almost all genera are known from Brazil: Elidiptera Spinola (Brazil, Central America), Messeis Stål (Brazil, Central America), Paraphradmon Fennah (Brazil), Prinoessa Fennah (Guyana), Metaphradmon Fennah (Brazil), Parelidiptera Fennah (Brazil), Nelidia Stål (Brazil) and Flatachilus Fennah (Brazil). Presently Myconellus tucumanus Fennah (Myconini) is the only Achilidae species recorded from Argentina.

In this paper a new Achilini genus represented by a new species is described, based on specimens collected in 2007 at Pucará in Lanin National Park on the coast of Lacar Lake (Neuquén Province, Argentina). 